\title{
PRACTICE PARAMETER: ANTICONVULSANT PROPHYLAXIS IN PATIENTS WITH NEWLY DIAGNOSED BRAIN TUMORS
}

\author{
Report of the Quality Standards Subcommittee of the American Academy of Neurology \\ M.J. Glantz, MD; B.F. Cole, PhD; P.A. Forsyth, MD; L.D. Recht, MD; P.Y. Wen, MD; \\ M.C. Chamberlain, MD; S.A. Grossman MD; and J.G. Cairncross, MD
}

\begin{abstract}
Overview. The Quality Standards Subcommittee seeks to develop scientifically sound, clinically relevant practice parameters for the practice of neurology. Practice parameters are strategies for patient management that assist physicians in clinical decision making. A practice parameter is one or more specific recommendations based on analysis of evidence on a specific clinical problem. These might include diagnosis, symptoms, treatment, or procedure evaluation. American Academy of Neurology (AAN) members have requested the publication of a practice parameter on the use of prophylactic anticonvulsants in patients with primary and metastatic brain tumors.
\end{abstract}

Justification. Physicians often administer anticonvulsant medication prophylactically to patients with brain tumors, despite the lack of definitive evidence that prophylactic anticonvulsant therapy is effective in preventing first seizures. ${ }^{1-4}$ If anticonvulsant medications were free of side effects, their prophylactic use might be attractive even without such evidence. However, discomfort, expense, and inconvenience result from drug treatment and periodic monitoring of serum drug concentrations. Typical anticonvulsant-induced side effects, including cognitive impairment, myelosuppression, liver dysfunction, and dermatologic reactions (ranging from minor rashes to life-threatening Stevens-Johnson syndrome), appear to occur more frequently in patients with brain tumors than in other patient groups, ${ }^{3,5-16}$ although direct comparison studies have not been published. A spectrum of side effects unique to patients with brain tumors must also be considered. Phenytoin, carbamazepine, and phenobarbital reduce the efficacy of corticosteroids, ${ }^{17-21}$ which are administered almost universally to brain tumor patients. In addition, the ability of these anticonvulsants to stimulate the cytochrome P450 enzyme system results in markedly accelerated metabolism of a wide spectrum of chemotherapeutic agents including nitrosoureas, paclitaxel, cyclophosphamide, topotecan, irinotecan, thiotepa, 9-aminocampo-thecin, adriamycin, and methotrexate. ${ }^{22-34}$ As a result, inadequate chemotherapeutic dosing of brain tumor patients has been identified recently as a widespread and critically important problem. ${ }^{35}$ Conversely, corticosteroids and many chemotherapeutic agents alter the metabolism of anticonvulsants, making anticonvulsant under- and overdosing more common. ${ }^{35-45}$ The potential immunosuppressive effect of anticonvulsant medications represents an additional risk to this already immunocompromised patient population. ${ }^{46-49}$

In 1998, more than 170,000 patients were diagnosed with brain metastases, and more than 34,000 developed primary brain tumors. ${ }^{50-52}$ Twenty to $40 \%$ of all brain tumor patients have experienced a seizure by the time their brain tumor is diagnosed. ${ }^{3,411,12,14-16,53-61}$ In these patients, the need for anticonvulsant medication is clear. Patients who have not experienced a seizure remain at risk, however, and at least 20 to $45 \%$ more (depending on factors such as tumor histology, location, age, and treatment) will ultimately develop seizures. ${ }^{3,4,11-16,57-61}$ Because the number of newly diagnosed brain tumor patients is increasing yearly, ${ }^{62-65}$ the question of whether to administer prophylactic anticonvulsants is being posed to neurologists with increasing frequency by their patients and by colleagues in neurosurgery, internal medicine, oncology, and radiation oncology.

Although a number of studies have attempted to answer this question, ${ }^{3,11-14,56-60,66-68}$ these studies have used differing epidemiologic techniques, patient populations, treatment regimens, and outcome measures, and there remains no consensus among physicians about the optimum approach to this problem. Currently, the decision to administer

From the American Academy of Neurology, St. Paul, MN; the Departments of Medicine (Dr. Glantz) and Community Health (Dr. Cole), Brown University School of Medicine, Providence, RI; the Department of Medicine (Dr. Forsyth), Tom Baker Cancer Center, Alberta, Canada; the Department of Neurology (Dr. Recht), University of Massachusetts Medical School, Worcester, MA; the Department of Neurology (Dr. Wen), Brigham and Women's Hospital, Boston, MA; the Department of Neurology (Dr. Chamberlain), Kaiser Permanente, Baldwin Park, CA; the Department of Oncology (Dr. Grossman), Johns Hopkins Oncology Center, Baltimore, MD; and the Department of Medical Oncology (Dr. Cairncross), London Regional Cancer Centre, Ontario, Canada.

Approved by the Quality Standards Subcommittee October 9, 1999. Approved by the Practice Committee January 15, 2000. Approved by the AAN Board of Directors February 26, 2000.

Received November 30, 1999. Accepted in final form January 6, 2000.

Address correspondence and reprint requests to The American Academy of Neurology, 1080 Montreal Avenue, St. Paul, MN 55116.

Copyright (C) 2000 by the American Academy of Neurology 
prophylactic anticonvulsants to patients with brain tumors is based primarily on preference rather than clinical evidence, and varies by physician training and experience (table 1). Reliable guidelines, based on a critical review of the literature, are needed.

Description of process. Pertinent studies were identified through MEDLINE searches of the years 1966 to July 1999 using the search parameters SEIZURE (exp), BRAIN NEOPLASMS (exp), ANTICONVULSANTS (exp), CRANIOTOMY (exp), and PRIMARY PREVENTION (exp). All 829 articles identified in this way were reviewed, and all studies, including randomized clinical trials, cohort studies, and case series, that considered the prophylactic use of anticonvulsants in patients with brain tumors were selected. The reference list of each of the selected papers was reviewed for additional pertinent studies. CANCERLIT and the Cochrane Database were also queried. Lastly, all abstracts indexed under "seizure," "brain tumor," or "anticonvulsant," which appeared in the American Society of Clinical Oncology, American Academy of Neurology, American Neurologic Association, American Epilepsy Society, and American Association of Neurologic Surgeons abstract books between the years 1982 and 1999, were reviewed. When overlapping data were published more than once (for example, as a preliminary communication and subsequently, with additional patients, in final form) only the most updated version was selected. Two studies ${ }^{66,67}$ addressed the issue of prophylactic anticonvulsant use in patients with a variety of neurologic conditions, including patients with brain tumors, but neither the published data nor queries to the anthors ultimately allowed separation of patients with brain tumors from those with other diagnoses. In a third study, prophylactic anticonvulsant medication was administered, and follow-up was carried out for only 3 postoperative days. ${ }^{68}$ These studies were excluded.

Studies included in the final analysis were then classified according to their level of evidence using published standards $^{69,70}$ (Appendix). Reported seizure frequencies for patients in the anticonvulsant prophylaxis and nonprophylaxis groups in each study were compared by calculating odds ratios (ORs) and $95 \%$ confidence intervals $(95 \% \mathrm{CIs})$. In two studies, the ORs were uninformative because none of the patients had seizures in either the anticonvulsant-treated ${ }^{14}$ or untreated $^{12}$ groups (i.e., ORs of 0 and infinity respectively). For these two studies, reported seizure frequencies for patients in the anticonvulsant prophylaxis and nonprophylaxis groups were compared using Fisher's exact test to accommodate studies with small numbers of seizures.

A meta-analysis was conducted on seizure incidence using all identified prospective, randomized clinical trials. Seizure-free survival (time to first seizure or death, whichever occurred first) and overall survival (time to death) were also calculated for the two studies from which patient-level data were available. ${ }^{15,16}$

For each end point in each trial, an QR, comparing the odds of the event in the anticonvulsant prophylaxis group relative to the control group, was computed. The trial-specific ORs were then averaged to provide a meta-analysis summary. The meta-analysis OR was used subsequently to test whether anticonvulsant prophylaxis affected the odds of an event. All statistical tests were performed using a $\mathrm{Z}$ test. Two-sided $p$ values were used to compare the treatment groups with respect to the odds of an event. A $p$ value less than 0.05 was considered significant.

For each clinical trial used in the seizure incidence analysis, the OR describing the odds of seizure in the anticonvulsant group relative to the control group was computed along with the variance (V) of $\log (\mathrm{OR})$, and a $95 \% \mathrm{CI}$ for the OR estimate. These computations were performed using standard techniques. ${ }^{71}$ The meta-analysis OR was then obtained by computing the weighted average of the $\log (\mathrm{OR})$ estimates, for which the weightings were defined by the inverse variance $(1 / \mathrm{V})$ of $\log (\mathrm{OR})$ for each trial. In this way, each trial was weighted inversely according to the amount of variation associated with the $\log (\mathrm{OR})$ estimate. The standard error of the weighted average was obtained by dividing the sum of the weighting into one. The weighted average was then "exponentiated" to obtain the overall summary OR. Statistical inference was carried out on the $\log (\mathrm{OR})$ scale using normal $(\mathrm{Z})$ distribution theory. ${ }^{71}$

The meta-analysis of seizure-free survival was performed using previously established techniques. ${ }^{72}$ For each clinical trial the Kaplan-Meier method ${ }^{73}$ was used to estimate seizure-free survival according to treatment group. The treatment comparison was then made using the logrank test ${ }^{74}$ which evaluates the observed number of events (seizure or death) on each study arm compared with the number of events that would be expected to occur if each treatment group had the same risk. The logrank analyses were then averaged to obtain a meta-analysis comparison of the treatment groups in terms of an OR. The meta-analysis of overall survival was conducted in a similar fashion.

Results. Twelve studies were identified that provided data on the frequency of first seizures in patients with brain tumors relative to the treatment of interest (prophylactic anticonvulsant use versus no prophylactic anticonvulsants). Of these, four were randomized clinical trials that provided level I evidence, ${ }^{15,16,60,61}$ and eight were cohort studies that provided level II evidence $e^{3,11-14,57-59}$ (table 2). One trial accrued patients from three participating centers ${ }^{16}$; the remainder were single-institution studies. Eleven of the 12 studies had no patients lost to follow-up. The remaining study ${ }^{61}$ reported 6 of 
Table 2 Anticonvulsant prophylaxis studies in patients with brain tumors

\begin{tabular}{|c|c|c|c|c|c|c|}
\hline \multirow[b]{2}{*}{ Reference } & \multirow[b]{2}{*}{ Tumor type } & \multirow[b]{2}{*}{$\mathrm{n}$} & \multirow[b]{2}{*}{ Anticonvulsant } & \multicolumn{2}{|c|}{ Patients with seizures/total (\%) } & \multirow[b]{2}{*}{ OR $(95 \% \mathrm{CI})^{*}$ or $p$ value } \\
\hline & & & & Drug group & Placebo group & \\
\hline \multicolumn{7}{|c|}{ Trials providing level I evidence } \\
\hline Forsyth ${ }^{16}$ & Metastasis $\dagger$ & 100 & Dilantin & $11 / 46(24)$ & $15 / 54(28)$ & $0.82(0.33-2.01)$ \\
\hline Glantz $z^{15}$ & $\begin{array}{l}\text { Metastasis, } \uparrow \\
\text { glioma }\end{array}$ & 74 & Depakote & $13 / 37(35)$ & $9 / 37(24)$ & $1.69(0.61-4.63)$ \\
\hline Franceschetti $^{60}$ & $\begin{array}{l}\text { Metastasis, } \S \\
\text { glioma, } \\
\text { meningioma }\end{array}$ & 639 & $\begin{array}{l}\text { Dilantin or } \\
\text { phenobarbital }\end{array}$ & $3 / 41(7) \|$ & $4 / 22(18) \|$ & $0.36(0.07-1.76)$ \\
\hline \multirow[t]{5}{*}{ North $^{61}$} & Meningioma & $81 \#$ & Dilantin & $2 / 10(20)$ & $2 / 9(22)$ & \\
\hline & Metastasis & & & $3 / 6(50)$ & $2 / 7(29)$ & \\
\hline & Glioma & & & $3 / 16(19)$ & $1 / 16(6)$ & \\
\hline & Sellar Tumor & & & $1 / 10(10)^{* *}$ & $0 / 7(0)$ & \\
\hline & Total & & & $9 / 42(21)$ & $5 / 39(13)$ & $1.85(0.56-6.12)$ \\
\hline \multicolumn{7}{|c|}{ Trials providing level II evidence } \\
\hline Moots $^{14}$ & Glioma & 36 & Not recorded & $0 / 4(0)$ & $10 / 32(31)$ & $p=0.60$ \\
\hline Byrne $^{57}$ & Melanoma & 63 & Not recorded & $2 / 12(17)$ & $19 / 51(37)$ & $0.34(0.07-1.70)$ \\
\hline Hagen $^{12}$ & Melanoma & 22 & Dilantin, others & $3 / 19(16)$ & $0 / 3(0)$ & $p=1.00$ \\
\hline Hung $^{13}$ & Metastasis & 68 & Dilantin & $2 / 20(10)$ & $6 / 48(12.5)$ & $0.78(0.14-4.23)$ \\
\hline Cohen $^{3}$ & Metastasis & 133 & Dilantin & $8 / 61(13.1)$ & $8 / 72(11.1)$ & $1.21(0.42-3.43)$ \\
\hline \multicolumn{7}{|c|}{ Trials providing level II evidence } \\
\hline Boarini ${ }^{59}$ & Glioma & 71 & Phenobarbital & $7 / 33(21)$ & $15 / 38(39)$ & $0.41(0.14-1.19)$ \\
\hline Mahaley $^{11}$ & Glioma & 59 & Dilantin & $15 / 38(39)$ & $6 / 21(28)$ & $1.63(0.52-5.14)$ \\
\hline Dent $^{58}$ & Metastasis & 247 & Not recorded & $11 / 64(17)$ & $13 / 183(7)$ & $2.71(1.15-6.41)$ \\
\hline
\end{tabular}

* Odds ratio (OR) and 95\% confidence interval (CI). $p$ Values for two studies calculated using Fisher's exact test.

$\dagger$ Includes patients with metastases $(n=60)$ and gliomas $(n=40)$.

+ Includes patients with metastases $(\mathrm{n}=59)$ and gliomas $(\mathrm{n}=15)$.

$\S$ Includes meningiomas $(\mathrm{n}=27)$, gliomas $(\mathrm{n}=23)$, and metastases $(\mathrm{n}=13)$

ๆ Excludes 65 patients with preoperative seizures.

$\|$ Follow-up for the first postoperative week only.

\# Excludes 200 patients with nonmalignant lesions: aneurysm $(n=55)$, head injury $(n=100)$, ventriculoatrial shunt $(n=25)$, and other $(n=20)$.

** The one patient in this group with a seizure had a pituitary adenoma.

281 patients $(2.1 \%)$ lost to follow-up, but this number includes all patients studied: 81 with brain tumors and 200 with other brain lesions. Specific numbers for the 81 brain tumor patients are not available. Median follow-up could be determined for six of the 12 studies: 5.44 months, ${ }^{16} 7$ months, ${ }^{15} 8$ months, ${ }^{14} 14$ months, ${ }^{59} 14.5$ months, ${ }^{12}$ and 19 months. ${ }^{11}$ In all studies, patients with previous seizures or prior use of anticonvulsant medication were excluded.

Only one of the 12 studies $^{58}$ reported a significant difference in seizure frequency between the anticonvulsant prophylaxis and nonprophylaxis groups, and this difference favored the nonprophylaxis group (i.e., a lower seizure frequency was seen in the nonprophylaxis group). A trend in favor of the nonprophylaxis group was seen in two of the four randomized studies, and three of the other seven nonrandomized studies. In the three studies (two randomized clinical trials ${ }^{15,16}$ and one cohort study ${ }^{3}$ ) that addressed this issue, no clinical or laboratory variable, including age, Karnofsky performance status, supratentorial tumor location, tumor histology, number of brain lesions, presence of hemorrhage, history of brain surgery, or pretreatment EEG was a significant predictor of first seizure occurrence.

Table 3 shows the seizure incidence and seizure-free survival results for each clinical trial considered in the metaanalysis, and for the meta-analysis summary. None of the trials provided statistical evidence of an effect of anticonvulsant prophylaxis on seizure incidence or seizure-free survival. The meta-analysis result confirms these findings, with an overall OR of $1.09(95 \%$ CI, 0.63 to $1.89 ; p=0.8)$ for seizure incidence and of 1.03 (95\% CI, 0.74 to $1.44 ; p=0.9$ ) for seizure-free survival. There was also no effect of anticonvulsant prophylaxis on overall survival in the two trials that examined this question ( $p=0.5$ in one ${ }^{16}$ and $p=0.2$ in the other ${ }^{15}$ ) or in the meta-analysis of overall survival (OR, $0.93 ; 95 \%$ CI, 0.65 to $1.32 ; p=0.7$ ).

Review of the 12 studies included in this analysis provided additional information pertinent to the issue of prophylactic anticonvulsant use in patients with brain tumors (table 4). Consistent with the literature, these studies recorded, in aggregate, a 26\% incidence of seizures at or before brain tumor diagnosis (range, 14 to 51\%), and a 19\% incidence of seizures after brain tumor diagnosis (range, 10 to 45\%). Seizures were more common, both before and after brain tumor diagnosis, in patients with primary compared with metastatic brain tumors. Of those seizures that occurred after brain tumor diagnosis, the initial seizure was a generalized tonic-clonic convulsion in $42 \%$ of patients (range, 10 to $77 \%$ ). Among the eight cohort studies (in which prophylactic anticonvulsant use was determined by individual physician preference), $43 \%$ of patients received prophylaxis - $63 \%$ of patients with primary and $32 \%$ of patients with metastatic brain tumors. ${ }^{3,11-14,57-59}$ In the seven studies in which drug levels were examined at the time of a seizure, $42 \%$ of patients receiving anticonvulsant prophylaxis had a subtherapeutic level. ${ }^{3,12,14-16,59,60}$ In the six studies that recorded information on the frequency and severity of anticonvulsant side effects, ${ }^{11-16} 23.8 \%$ of patients (range, 5 to $38 \%$ ) experienced side 
effects severe enough to warrant a change in or discontinuation of anticonvulsant therapy. These side effects included rash (14\%), nausea or vomiting $(5 \%)$, encephalopathy (5\%), myelosuppression (3\%), and ataxia, increased liver enzymes, or gum pain $(5 \%)$.

Summary. Twelve studies have examined, either in randomized controlled trials ${ }^{15,16,60,61}$ or cohort studies, , $^{3,11-}$ $14,57-59$ the ability of prophylactic anticonvulsants to prevent first seizures in patients with brain tumors, and none have demonstrated efficacy. Four of these studies ${ }^{15,16,60,61}$ provide level I evidence. A meta-analysis of these four studies also revealed no evidence of an effect on the frequency of first seizures in patients receiving anticonvulsant prophylaxis. In contrast, deleterious interactions with cytotoxic drugs and corticosteroids are a major concern, and the incidence and severity of anticonvulsant side effects appear to be appreciably higher (20 to 40\%) in brain tumor patients than in the general population of patients receiving anticonvulsants. ${ }^{6-16,75}$ This increased incidence is due at least in part to the additive or synergistic effects of concurrently administered drugs (especially chemotherapeutic agents) and to the underlying brain tumor.

Conclusions. Seizures are a common and sometimes devastating complication of brain tumors, and meticulous attention to their diagnosis and treatment is critical. The available evidence suggests, however, that prophylactic administration of anticonvulsant medications does not provide substantial benefit (i.e., a risk reduction of $26 \%$ or more for seizure-free survival), whereas anticonvulsant-associated side effects are especially common and occasionally life-threatening.

Many patients who experienced seizures while receiving anticonvulsant prophylaxis had subtherapeutic anticonvulsant blood levels. Although this may provide one explanation for the ineffectiveness of anticonvulsant prophylaxis in some patients, it did not change the conclusions of the one randomized controlled trial that addressed that issue specifically. ${ }^{15}$ In that study, $23 \%$ of patients receiving anticonvulsant prophylaxis who experienced a seizure had subtherapeutic levels. Reanalysis excluding patients with subtherapeutic levels still showed no benefit for anticonvulsant prophylaxis. Moreover, even in the setting of scrupulously monitored prospective studies in epileptic patients, subtherapeutic levels are extremely common, partly because of drug interactions. ${ }^{76}$ Rather than change the implications of these studies, this high rate of subtherapeutic levels simply reflects a clinical reality.

The meta-analysis technique itself is not infallible. Its value depends on the quality of its component studies. ${ }^{77} \mathrm{~A}$ meta-analysis cannot evaluate or correct for bias in its component studies, and can provide misleading results if the component studies are very heterogeneous with respect to patient characteristics, the disease studied, or the intervention. The studies included in the current meta-analysis were all prospective, randomized, and controlled-the most effective strategy for minimizing the risk of bias and confounding. As described in the Description of process and Results sections, and as summarized in table 2, the studies were evaluated specifically to ensure good patient homogeneity. For these reasons, this meta-analysis does provide a reliable estimate of the overall lack of effect of anticonvulsant prophylaxis in patients with brain tumors.

\section{Recommendations.}

1. In patients with newly diagnosed brain tumors, anticonvulsant medications are not effective in preventing first seizures. Because of their lack of efficacy and their potential side effects, prophylactic anticonvulsants should not be used routinely in patients with newly diagnosed brain tumors (standard).

2. In patients with brain tumors who have not had a seizure, tapering and discontinuing anticonvulsants after the first postoperative week is appropriate, particularly in those patients who are medically stable and who are experiencing anticonvulsant-related side effects (guideline).

Future research. Important clinical questions remain to be answered by future studies. Are other anticonvulsants besides phenytoin, phenobarbital, and valproic acid effective in preventing first seizures in patients with brain tumors? Phenytoin and phenobarbital are the most widely used anticonvulsants for seizure prophylaxis, and 11 of the 12 studies reviewed in this paper employed one or both of these agents either exclusively or primarily. One of the 12 studies (a prospective randomized trial) used valproic acid. ${ }^{15}$ These three anticonvulsants operate through different molecular mechanisms to prevent seizures, and together represent three primary mechanisms through which drug-mediated anticonvulsant effects are thought to be exerted. Prospective randomized studies would be required, however, to evaluate definitively the efficacy of the newer anticonvulsant medications in this setting. 
Table 4 Ancillary data from anticonvulsant prophylaxis studies in patients with brain tumors

\begin{tabular}{|c|c|c|c|c|c|}
\hline \multirow[b]{2}{*}{ Reference } & \multirow[b]{2}{*}{ Tumor type } & \multicolumn{2}{|c|}{ Seizure frequency, $\mathrm{n} /$ total $(\%)$} & \multirow{2}{*}{$\begin{array}{c}\text { Elective } \\
\text { anticonvulsant use, } \\
\text { n/total (\%) }\end{array}$} & \multirow{2}{*}{$\begin{array}{c}\text { Patients with seizures } \\
\text { and subtherapeutic } \\
\text { anticonvulsant levels, } \\
\text { n/total (\%) }\end{array}$} \\
\hline & & Presentation & Subsequently & & \\
\hline Byrne $^{57}$ & Melanoma & $17 / 80(21)$ & $21 / 63(33)$ & $12 / 63(19)$ & - \\
\hline Hagen $^{12}$ & Melanoma & $13 / 35(37)$ & $3 / 22(14)$ & $19 / 22(86)$ & $3 / 3(100)$ \\
\hline Hung $^{13}$ & Metastases & - & $8 / 68(12)$ & $20 / 68(29)$ & - \\
\hline Cohen $^{3}$ & Metastases & 35/195 (18) & $16 / 160(10)$ & $64 / 160(40)$ & $4 / 6(67)$ \\
\hline Boarini $^{59}$ & Astrocytomas & - & $22 / 71(31)$ & $33 / 68(49)$ & $5 / 7(71)$ \\
\hline Mahaley $^{11}$ & Astrocytomas & $41 / 100(41)$ & $21 / 59(36)$ & $38 / 59(64)$ & - \\
\hline Dent $^{58}$ & Metastases & $41 / 288(14)$ & $24 / 247(10)$ & $64 / 247(26)$ & - \\
\hline \multirow[t]{4}{*}{ North $^{61}$} & Meningioma & - & $4 / 19(21)$ & - & - \\
\hline & Metastases & - & $5 / 13(38)$ & - & - \\
\hline & Glioma & - & $4 / 32(13)$ & - & - \\
\hline & Sellar tumor & - & $1 / 17(6)$ & - & - \\
\hline \multirow[t]{2}{*}{ Forsyth $^{16}$} & Astrocytomas & - & $17 / 40(43)$ & 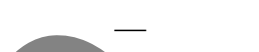 & 4/11 (36) \\
\hline & Metastases & - & $9 / 60(15)$ & & - \\
\hline \multirow[t]{3}{*}{ Glantz $^{15}$} & Astrocytomas & - & $5 / 11(45)$ & & $3 / 13(23)$ \\
\hline & Metastases & - & & & - \\
\hline & Both & 13/91 (14) & & & - \\
\hline Franceschetti ${ }^{60}$ & All & $65 / 128(51)$ & & - & $2 / 3(66)$ \\
\hline Moots $^{14}$ & Astrocytomas & $29 / 65(45)$ & & $32 / 36(89)$ & $1 / 10(10)$ \\
\hline \multirow[t]{3}{*}{ Total } & Astrocytomas & $70 / 165(42)$ & & $103 / 163(63)$ & - \\
\hline & Metastases & $106 / 598$ & (1) & $179 / 560(32)$ & - \\
\hline & All & $254 / 98$ & 187/981 (19) & $282 / 663(43)$ & $22 / 53(42)$ \\
\hline
\end{tabular}

Are there differences between specific subgroups of patients with brain tumors with regard to prevention of first seizures? Some subgroups of patients with brain tumors (e.g., those with melanoma, hemorrhagic lesions, multiple metastases, tumors located near the Rolandic fissure, slow-growing primary brain tumors) have a higher risk of developing seizures. ${ }^{4,14,56,78-81}$ There is no evidence that anticonvulsant prophylaxis is more effective in any of these subgroups than in the population of patients with brain tumors as a whole, but prospective, randomized trials tailored specifically to these subgroups should be performed.

Does performance of a neurosurgical procedure influence the need for or the efficacy of prophylactic anticonvulsants in patients with brain tumors? Most patients with primary brain tumors, and increasing numbers of patients with brain metastases, undergo a neurosurgical procedure (craniotomy or stereotactic biopsy) at the time of brain tumor diagnosis, and are placed on anticonvulsant medication during the perioperative period. Individual studies (including randomized clinical trials in patients with brain tumors) have either found no efficacy of prophylactic anticonvulsants at any point in the postcraniotomy setting or have shown a limited duration of benefit (no more than 72 days). ${ }^{15,16,61,67}$ Similarly, a meta-analysis of randomized clinical trials found no benefit for anticonvulsant prophylaxis in preventing postcraniotomy seizures in patients without preexisting seizures. ${ }^{82}$ Prophylactic anticonvulsants also fail to reduce the frequency of post-traumatic seizures beyond the first week after head injury. ${ }^{83-85}$ However, because of methodological shortcomings in the pertinent studies, including small numbers of patients in the brain tumor studies, additional corroborative studies are warranted.

What recommendations can be made about the safe operation of motor vehicles in patients with brain tumors? Driving is a critical concern for patients, their families, and their physicians, and there are no data that address specifically the issue of anticonvulsant prophylaxis and suitability for driving in patients with brain tumors. Because of their lack of demonstrated efficacy in preventing first seizures, prophylactic anticonvulsants do not make driving any safer in patients who have never experienced a seizure. Frequently, neurologic deficits related to the tumor or its treatment, rather than the risk of seizures, constitute the primary barrier to safe operation of a motor vehicle. Legal considerations, which vary by state, will also influence recommendations regarding driving. Further research is needed.

Disclaimer. This statement is provided as an educational service of the AAN. It is based on an assessment of current scientific and clinical information. It is not intended to include all possible proper methods of care for a particular 
neurologic problem or all legitimate criteria for choosing to use a specific procedure. Neither is it intended to exclude any reasonable alternative methodologies. The AAN recognizes that specific patient care decisions are the prerogative of the patient and the physician caring for the patient, based on all of the circumstances involved.

\section{Acknowledgment}

The authors thank Jacqueline French, MD for facilitating this project; the members of the Quality Standards Subcommittee for providing their expertise, time, and insight into the development of this document; and Wendy Edlund, the AAN Clinical Policy Administrator, for her patience and guidance in developing this practice parameter.

The authors and the subcommittee also thank the numerous individuals, AAN Sections, and organizations that reviewed drafts of this practice parameter, including the American Association of Neurological Surgeons, and the AB Baker, Child Neurology, Clinical Neurophysiology, Critical Care and Emergency Neurology, Epilepsy, Government Service, Interventional Neurology, Movement Disorders, Neuroepidemiology, Neurological Rehab, Neuro-Oncology, Pain, and Spine Sections of the AAN.

\section{Appendix 1 \\ Quality of evidence definitions}

Class I: Evidence provided by one or more well-designed randomized, controlled clinical trials, including overviews (metaanalyses) of such trials

Class II: Evidence provided by one or more well designed observational studies with concurrent controls such as casecontrol or cohort studies

Class III: Evidence provided by expert opinion, case series, case reports, and studies with nonrandomized historical controls

\section{Strength of recommendations}

Standard: A principle for patient management that reflects a high degree of clinical certainty. Usually this requires class I evidence that addresses directly the clinical question, or overwhelming class II evidence when circumstances preclude randomized clinical trials.

Guideline: A recommendation for patient management that reflects moderate clinical certainty. Usually this requires class II evidence or a strong consensus of class III evidence.

Practice option: A strategy for patient management for which the clinical utility is uncertain because of inconclusive or conflicting evidence or opinion.

\section{Appendix 2}

American Academy of Neurology Quality Standards Subcommittee members: Gary Franklin, MD, MPH-Co-Chair; Catherine Zahn, MD - Co-Chair; Milton Alter, MD, PhD; Stephen Ashwal, MD;John Calverley, MD; Richard Dubinsky, MD; Jacqueline French, MD (facilitator); Michael Greenberg, MD; Gary Gronseth, MD; Deborah Hirtz, MD; Robert Miller, MD; and James Stevens, MD.

\section{References}

1. Kvam DA, Loftus CM, Copeland B, et al. Seizures during the immediate postoperative period. Neurosurgery 1983;12:14-17.

2. Deutschman CS, Haines SJ. Anticonyulsant prophylaxis in neurological surgery. Neurosurgery 1985;17:510-517.

3. Cohen N, Strauss G, Lew R, et al. Should prophylactic anticonvulsants be administered to patients with newly-diagnosed cerebral metastases? A retrospective analysis. J Clin Oncol 1988;6:1621-1624.

4. Posner JB. Neurologic complications of cancer. Philadelphia: FA Davis, 1995.

5. Delattre J, Safai B, Posner JB. Erythema multiforme and Stevens-Johnson syndrome in patients receiving cranial irradiation and phenytoin. Neurology 1988;38:194-198.

6. Taylor LP, Posner JB. Phenobarbital rheumatism in patients with brain tumor. Ann Neurol 1989;25:92-94.

7. Khe HX, Delattre JY, Poisson M. Stevens-Johnson syndrome in a patient receiving cranial irradiation and carbamazepine. Neurology 1990;40:1144-1145.

8. Borg MF, Probert JC, Zwi LJ. Is phenytoin contraindicated in patients receiving cranial irradiation? Australas Radiol 1995;39:4246.

9. Cockey GH, Amann ST, Reents SB, et al. Stevens-Johnson syndrome resulting from whole-brain radiation and phenytoin. Am J Clin Oncol 1996;19:32-34.

10. Lehmann DF, Hurteau TE, Newman N, et al. Anticonvulsant usage is associated with an increased risk of procarbazine hypersensitivity reactions in patients with brain tumors. Clin Pharmacol Therapeutics 1997;62:225-229.

11. Mahaley MS, Dudka L. The role of anticonvulsant medications in the management of patients with anaplastic gliomas. Surg Neurol 1981;16:399-401.

12. Hagen NA, Cirrincione C, Thaler HT, et al. The role of radiation therapy following resection of single brain metastasis from melanoma. Neurology 1990;40:158-160.

13. Hung S, Hilsenbeck S, Feun L. Seizure prophylaxis with phenytoin in patients with brain metastases. Proc Am Soc Clin Oncol 19991;10:A1151. Abstract.

14. Moots PL, Maciunas RJ, Eisert DR, et al. The course of seizure disorders in patients with malignant gliomas. Arch Neurol $1995 ; 52: 717-724$.

15. Glantz MJ, Cole BF, Friedberg MH, et al. A randomized, blinded, placebo-controlled trial of divalproex sodium prophylaxis in adults with newly diagnosed brain tumors. Neurology 1996;46:985-991. 
16. Forsyth PA, Weaver S, Fulton D, et al. A prospective randomized study of prophylactic anticonvulsants in patients with primary or metastatic brain tumors and without prior seizures. J Neurooncol 2000 (in press).

17. Haque N, Thrasher K, Werk E. Studies on dexamethasone metabolism in man: effect of diphenylhydantoin. J Clin Endocrinol Metab 1972;34:44-50.

18. Gambertoglio JG, Holford NH, Kapusnik JE, et al. Disposition of total unbound prednisolone in renal transplant patients receiving anticonvulsants. Kidney Int $1984 ; 25: 119-123$.

19. Chalk JB, Ridgeway K, Brophy T, et al. Phenytoin impairs the bioavailability of dexamethasone in neurological and neurosurgical patients. J Neurol Neurosurg Psychiatry 1984;47:1087-1090.

20. Dropcho EJ, Soong S. Steroid-induced weakness in patients with primary brain tumors. Neurology 1991;41:1235-1239.

21. Wassner SJ, Malekzadem MH, Pennisi AJ, et al. Allograft survival in patients receiving anticonvulsant medications. Clin Nephrol 1977;8:293-297.

22. Reich SD, Bachur NR. Alterations in adriamycin efficacy by phenobarbital. Cancer Res 1976;36:3803-3806.

23. Warren RD, Bender AR. Drug interactions with antineoplastic agents. Cancer Treat Rep 1977;61:1231-1241.

24. Gilbert MR, Grossman SA, Mikkelson T, et al. The impact of anticonvulsants on CPT-11 dose in patients with recurrent malignant glioma. Neurooncology 1999;1:313. Abstract.

25. Levin VA, Stearns J, Byrd A, et al. The effect of phenobarbital pretreatment on the antitumor activity of 1,3-bis(2-chloroethyl)-1nitrosourea (BCNU), 1-(2-chlorethyl)-3-cyclohexyl-1-nitrosourea (CCNU) and 1-(2-chlorethyl)-3-(2,6-dioxo-3-piperidyl-1nitrosourea (PCNU), on the plasma pharmacokinetics and biotransformation of BCNU. J Pharmacol Exp Ther 1979;208:1-6.

26. Muller PJ, Tator $\mathrm{CH}$, Bloom M. The effect of phenobarbital on the toxicity and tumoricidal activity of CCNU in a murine brain tumor model. J Neurosurg 1980;52:359-366.

27. Workman P, Bleehen NM, Wiltshire CR. Phenytoin shortens the half-life of the hypoxic cell radiosensitizer misonidazole in man: implications for possible reduced toxicity. Br J Cancer 1980;41:302-304.

28. Fitzsimmons WE, Ghalie R, Kaizer H. The effect of hepatic enzyme inducers on busulfan neurotoxicity. Cancer Chemother Pharmacol 1990;27:226-228.

29. Baker DK, Relling MV, Pui C-H, et al. Increased teniposide clearance with concomitant anticonvulsant therapy. J Clin Oncol 1992;10:311-315.

30. Friedman AH, Ashley DM, Kerby T, et al. Topotecan treatment of adults with primary malignant glioma. Proc Am Soc Clin Oncol 1998;17:390A. Abstract.

31. Chang TK, Chen G, Waxman DJ. Modulation of thiotepa antitumor activity in viyo by alteration of liver cytochrome P450catalyzed drug metabolism. J Pharmacol Exp Ther 1995;274:270-275.

32. Fetell MR, Grossman SA, Fisher JD, et al. Preirradiation paclitaxel in glioblastoma multiforme: efficacy, pharmacology, and drug interactions. J Clin Oncol 1997;15:3121-3128.

33. Grossman SA, Hochberg F, Fisher J, et al. Increased 9-aminocamptothecin dose requirements in patients on anticonvulsants. Cancer Chemother Pharmacol 1998;42:118-126.

34. Chang SM, Kuhn JG, Rizzo J, et al. Phase I study of paclitaxel in patients with recurrent malignant gliomas: a North American Brain Tumor Consortium report. J Clin Oncol 1998; 16:2188-2194.

35. Glantz MJ, Kim L, Choy H, Akerley W. Concurrent chemotherapy and radiotherapy in patients with brain tumors. Oncology 1999; 13:78-82.

36. Finchum RW, Schottelius DD. Decreased phenytoin levels in antineoplastic therapy. Ther Drug Monit 1979;1:277-283.

37. Perucca E. Pharmacokinetic interactions with antiepileptic drugs. Clin Pharmacokinet 1982;7:57-84.

38. Sylvester RK, Lewis FB, Caldwell KC, et al. Impaired phenytoin bioavailability secondary to cisplatinum, vinblastine and bleomycin. Ther Drug Monit 1984;6:302-305.

39. Neef C, Voogd-van der Straaten I. An interaction between cytostatic and anticonvulsant drugs. Clin Pharmacol Ther 1988;43:372375.

40. Jarosinski PF, Moslow JA, Alexander MS, et al. Altered phenytoin clearance during intensive treatment for acute lymphoblastic leukemia. J Pediatr 1988;112:996-999.

41. Grossman SA, Sheilder VR, Gilbert MR. Decreased phenytoin levels in patients receiving chemotherapy. Am J Med 1989;87:505510.

42. Lackner TE. Interaction of dexamethasone with phenytoin. Pharmacotherapy 1991;11:344-347.

43. Ghosh C, Lazarus HM, Hewlett JS et al. Fluctuation of serum phenytoin concentrations during autologous bone marrow transplant for primary central nervous system tumors. J Neurooncol 1992;12:25-32.

44. Rabinowicz AL, Hinton DR, Dyck P, et al. High-dose tamoxifen in treatment of brain tumors: interaction with antiepileptic drugs. Epilepsia 1995;36:513-515.

45. Gattis WA, May DB. Possible interaction involving phenytoin, dexamethasone, and antineoplastic agents: a case report and review. Ann Pharmacother 1996;30:520-526.

46. Sorrell TC, Forbes IJ. Depression of immune competence by phenytoin and carbamazepine: studies in vivo and in vitro. Clin Exp Immunol 1975;20:273-285.

47. Neuwelt EA, Kikuchi K, Hill S, et al. Immune responses in patients with brain tumors. Factors such as anti-convulsants that may contribute to impaired cell-mediated immunity. Cancer 1983;51:248-255.

48. Bardana EJ, Gabourel JD, Davies GH, et al. Effects of phenytoin on man's immunity: evaluation of changes in serum immunoglobulins, complement, and anti-nuclear antibody. Am J Med 1983;74:289-296.

49. Kikuchi K, McCormick CI, Neuwelt EA. Immunosuppression by phenytoin: implications for altered immune competence in brain tumor patients. J Neurosurg 1984;61:1085-1090.

50. Davis F, Surawicz T, Barlas S, Propp J. Central Brian Tumor Registry of the United States. Chicago: CBTRUS, 1997.

51. Posner JB. Management of brain metastases. Rev Neurol (Paris) 1992;148:477-487.

52. Landis SH, Murray T, Bolden S, Wingo PA. Cancer statistics, 1999. CA Cancer J Clin 1999;49:8-31. 
53. Simonescu MD. Metastatic tumors of the brain. A follow-up study of 195 patients with neurosurgical considerations. J Neurosurg 1960;17:361-373.

54. Zimm S, Wampler GL, Stablein D, et al. Intracerebral metastases in solid-tumor patients: natural history and results of treatment. Cancer 1981;48:384-394.

55. Gilbert MR, Grossman SA. Incidence and nature of neurologic problems in patients with solid tumors. Am J Med 1986;81:951954.

56. Glantz M, Recht L. Epilepsy in the cancer patient. In: Vinken PJ, Bruyn GW, eds. Neuro-oncology. Part III. Neurological disorders in systemic cancer. Handbook of clinical neurology, Vol 69. Amsterdam: Elsevier Publishing, 1997:9-18.

57. Byrne TN, Cascino TL, Posner JB. Brain metastasis from melanoma. J Neurooncol 1983;1:313-317

58. Dent S, Bociek G. Prophylactic anticonvulsants for cancer patients with newly diagnosed brain metastases. Proc Am Soc Clin Oncol 1996;15:529. Abstract.

59. Boarini DJ, Beck DW, VanGilder JC. Postoperative prophylactic anticonvulsant therapy in cerebral gliomas. Neurosurgery 1985;16:290-292.

60. Franceschetti S, Binelli S, Casazza M, et al. Influence of surgery and antiepileptic drugs on seizures symptomatic of cerebral tumours. Acta Neurochirur 1990;103:47-51.

61. North JB, Penhall RK, Hanieh A, et al. Phenytoin and postoperative epilepsy. A double-blind study. J Neurosurg 1983;58:672677.

62. Eby NL, Grufferman S, Flannelly CM, Schold SC, Vogel FS, Burger PC. Increasing incidence of primary brain lymphoma in the US. Cancer 1988;62:2461-2465.

63. Greig NH, Ries LG, Yanick R, Rapoport SI. Increasing annual incidence of primary malignant brain tumors in the elderly. J Natl Cancer Inst 1990;82:1621-1624.

64. Desmeules M, Middlesen T, Mao Y. Increasing incidence of primary malignant brain tumors: influence of diagnostic methods. J Natl Cancer Inst 1992;84:442-445.

65. Devesa SS, Bot WJ, Stone BJ, et al. Recent cancer trends in the United States. J Natl Cancer Inst 1995;87;175-181.

66. Matthew E, Sherwin AL, Welner SA, et al. Seizures following intracranial surgery: incidence in the first post-operative week. Can J Neurol Sci 1980;7:285-290.

67. Foy PM, Chadwick DW, Rajgopalan N, et al. Do prophylactic anticonvulsant drugs alter the pattern of seizures after craniotomy. J Neurol Neurosurg Psychiatry 1992;55:753-757.

68. Lee S-T, Lui T-N, Chang C-N, et al. Prophylactic anticonvulsants for prevention of immediate and early postcraniotomy seizures. Surg Neurol 1989;31:361-364.

69. Quality Standards Subcommittee of the American Academy of Neurology: Practice advisory. thrombolytic therapy for acute ischemic stroke---summary statement. Neurology 1996;47:835-839.

70. American Society of Clinical Oncology Ad Hoc Non-Small-Cell Lung Cancer Expert Panel. Clinical practice guidelines for the treatment of unresectable non-small-cell lung cancer. J Clin Oncol 1997;15:2996-3018.

71. Rosner B. Fundamentals of biostatistics. 4th ed. Belmont, CA:Wadsworth, 1995.

72. Early Breast Cancer Trialists' Collaborative Group: Effects of adjuvant tamoxifen and of cytotoxic therapy on mortality in early breast cancer. An overview of 61 randomized trials among 28,896 women. N Engl J Med 1988;319:1681-1692.

73. Kaplan EL, Meier P. Nonparametric estimation from incomplete observations. J Am Stat Assoc 1958;53:457-481.

74. Peto R, Pike MC, Armitage P, et al. Design and analysis of randomized clinical trials requiring prolonged observation of each patient. II. Analysis and examples. Br J Cancer 1977;35:1-39.

75. Landau J, Baulac M, Durand G, et al. Impairment of consciousness induced by valproate treatment following neurosurgical operation. Acta Neurochir 1993;125:92-96.

76. Leppik IE. Compliance during treatment of epilepsy. Epilepsia 1988;29(supp12):S79-S84.

77. Sacks HS, Berrier J, Reitman D, Ancona-Berk VA, Chalmers TC. Meta-analyses of randomized controlled trials. N Engl J Med 1987;316:450-455.

78. Deutschman CS, Haines SJ. Anticonvulsant prophylaxis in neurological surgery. Neurosurgery 1985;17:510-517.

79. Rasmussen T, Blundell J. Epilepsy and brain tumor. Clin Neurosurg 1959;7:138-158.

80. Berger MS, Ghatan S, Haglund MM, et al. Low grade gliomas associated with intractable epilepsy: seizure outcome utilizing electrocorticography during tumor resection. J Neurosurg 1993;79:62-69.

81. Giles FA, Sobell E, Leviton A, et al. Epidemiology of seizures in children with brain tumors. J Neurooncol 1992;12:53-68.

82. Kuijlen JMA, Teernstra OPM, Kessels AGH, et al. Effectiveness of antiepileptic prophylaxis used with supratentorial craniotomies: a meta-analysis. Seizure 1996;5:291-298.

83. Temkin NR, Dikmen SS, Anderson GD, et al. Valproate therapy for prevention of posttraumatic seizures: a randomized trial. J Neurosurg 1999;91:593-600.

84. Temkin NR, Dikmen SS, Wilensky AJ, et al. A randomized, double-blinded study of phenytoin for the prevention of posttraumatic seizures. N Engl J Med 1990;323:497-502.

85. Temkin NR, Haglund MM, Winn HR. Post-traumatic seizures. In: Youmans JR, ed. Neurological surgery. 4th ed. Philadelphia: WB Saunders, 1996:1834-1839. 


\title{
Neurology
}

\author{
Practice parameter: Anticonvulsant prophylaxis in patients with newly diagnosed brain \\ tumors [RETIRED]: Report of the Quality Standards Subcommittee of the American \\ Academy of Neurology \\ M.J. Glantz, B.F. Cole, P.A. Forsyth, et al. \\ Neurology 2000;54;1886-1893 \\ DOI 10.1212/WNL.54.10.1886
}

This information is current as of May 23, 2000

Updated Information \&
Services

Citations

Permissions \& Licensing

Reprints including high resolution figures, can be found at:

http://n.neurology.org/content/54/10/1886.full

This article has been cited by 20 HighWire-hosted articles:

http://n.neurology.org/content/54/10/1886.full\#\#otherarticles

Information about reproducing this article in parts (figures,tables) or in its entirety can be found online at:

http://www.neurology.org/about/about_the_journal\#permissions

Information about ordering reprints can be found online:

http://n.neurology.org/subscribers/advertise

Neurology ${ }^{\circledR}$ is the official journal of the American Academy of Neurology. Published continuously since 1951, it is now a weekly with 48 issues per year. Copyright . All rights reserved. Print ISSN: 0028-3878. Online ISSN:

$1526-632 X$

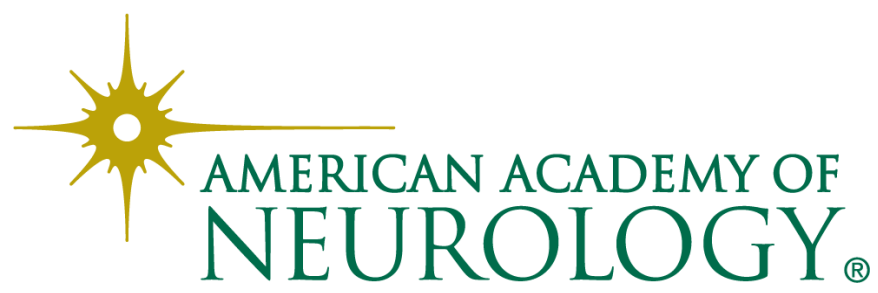

